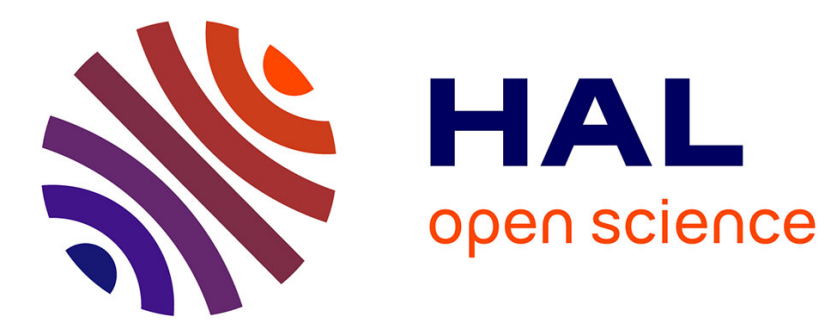

\title{
A cavity-backed dual polarized array of connected spiral antennas
}

\author{
Régis Guinvarc'H, Mohammed Serhir, Nicolas Ribière-Tharaud
}

\section{To cite this version:}

Régis Guinvarc'H, Mohammed Serhir, Nicolas Ribière-Tharaud. A cavity-backed dual polarized array of connected spiral antennas. 2012 IEEE International Symposium on Antennas and Propagation (APSURSI 2012), Jul 2012, Chicago, United States. pp.1-2, 10.1109/APS.2012.6348808 . hal-00773386

\section{HAL Id: hal-00773386 \\ https://hal-centralesupelec.archives-ouvertes.fr/hal-00773386}

Submitted on 16 Jan 2013

HAL is a multi-disciplinary open access archive for the deposit and dissemination of scientific research documents, whether they are published or not. The documents may come from teaching and research institutions in France or abroad, or from public or private research centers.
L'archive ouverte pluridisciplinaire HAL, est destinée au dépôt et à la diffusion de documents scientifiques de niveau recherche, publiés ou non, émanant des établissements d'enseignement et de recherche français ou étrangers, des laboratoires publics ou privés. 


\section{A cavity-backed dual polarized array of connected spiral antennas}

\author{
Régis Guinvarc'h \\ E3S/SONDRA \\ Supelec \\ Gif-Sur-Yvette, France
}

\author{
Mohammed Serhir \\ DRE, Laboratoire des Signaux et Systèmes (UMR 8506 : \\ Supelec - CNRS -Univ. Paris-Sud 11), \\ SUPELEC, 3 Rue Joliot-Curie, 91192 Gif-sur-Yvette, \\ Cedex France
}

\author{
Nicolas Ribière-Tharaud \\ line 1: dept. name (if applicable) \\ CEA \\ Gramat, France
}

\begin{abstract}
A connected array of spiral antennas with dual polarization and backed by a cavity is presented. A 5-elements array is measured using a simple, yet efficient, feeding technique. A low profile cavity is used to make the radiation unidirectional. First measurements show a good agreement between simulations and measurements.
\end{abstract}

\section{INTRODUCTION}

Spiral antennas are very wideband elements. However, placing them in an array greatly decrease the available bandwidth because of the grating globes appearance. This is even worst for a dual polarized array. In a recent paper [1], a new technique to enhance the lower limit of dual polarized array of spiral antennas has been introduced. Antennas of both polarizations are placed in an alternate configuration and are connected at the end of their arms. This configuration allows avoiding the reflections that usually occur at the end of the arms. These reflections are responsible for the lower frequency limit of the antenna bandwidth.

The concept used here has been introduced and studied from the electromagnetic simulation point of view in [1]. Then, experimental validation was still under investigations. Besides the antenna array design, the feeding system of spiral antennas is still an issue.

Indeed, the spiral antenna being symmetrical structure needs consequently a symmetrical excitation. In addition, the feed of the spiral must be matched to 188 ohms (theory) whereas the classical feed based on coaxial cable is non-symmetrical and is matched to 50 ohms (or 75 ohms).

In [1] a technique based on matched coaxial cable was recalled. We use here a different technique that allows a simple feed of the array. A last but important point which was not addressed in [1] is the case of the cavity. We present here a simple yet efficient cavity that gives a unidirectional beam with significant gain all over the bandwidth.

\section{PROTOTYPE}

\section{A. Array design}

The elementary spiral has two arms and is $72 \mathrm{~mm}$ in diameter. It has 4 turns. A 5-element array was built; cf. Figure 1, with a distance of $72 \mathrm{~mm}$ also from 2 centers. It is in the alternate configuration (Left handed, Right handed, Left handed, Right handed, Left handed). Straight connections are added between neighbouring spirals.

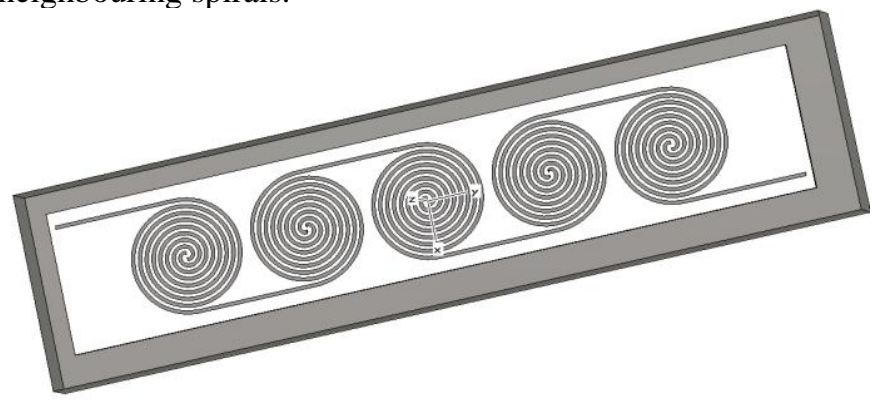

Figure 1: Front view of the prototype.

\section{B. Feeding}

Only the right handed elements are fed, the three others have a $120 \mathrm{ohms}$ resistor at their centers. The value of $120 \mathrm{ohms}$ is close to the impedance of the spirals when placed over a FR4 substrate with $1.6 \mathrm{~mm}$ thickness [Mc Faden]. The feeding circuit is made of two coaxial cables soldered together. The inner conductor of each cable is connected to one arm of a spiral. So the impedance between inner conductors (so seen from the antenna) is also about $120 \mathrm{ohms}$. On the other end of the coaxial cables, a $180^{\circ}$ hybrid is used to generate two signals in phase opposition.

\section{Cavity backing}

As can be seen in Figure 1, we have used a rectangular cavity. It is made of copper and its height is $5 / 8$ of the distance 
between the spirals and the bottom of the cavity, which is $31 \mathrm{~mm}$ (less than half the diameter of the spiral). This height has been used in order to suppress the coupling that would otherwise exist between the connections and the cavity. The cavity modes are outside the frequency range of interest. It is interesting to note that no absorbing material is used in the cavity.

\section{MEASUREMENTS AND SIMULATION RESULTS}

Only the Right handed spirals are fed, the three others have a 120 ohms resistor at their centers. The feeding circuit is made of two coaxial cables soldered together and connected to a $180^{\circ}$ hybrid to generate two signals in phase opposition. Doing this, we get a symmetrical and matched excitation for the spirals. In addition, this excitation technique can be generalized to symmetrical structures for which the input impedance is around $100 \mathrm{ohms}$.

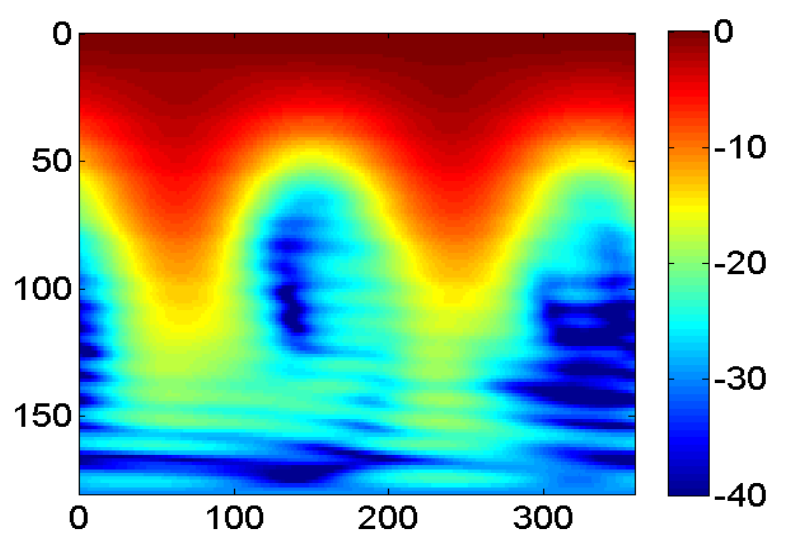

Figure 2: Normalized total gain at $1000 \mathrm{MHz}$

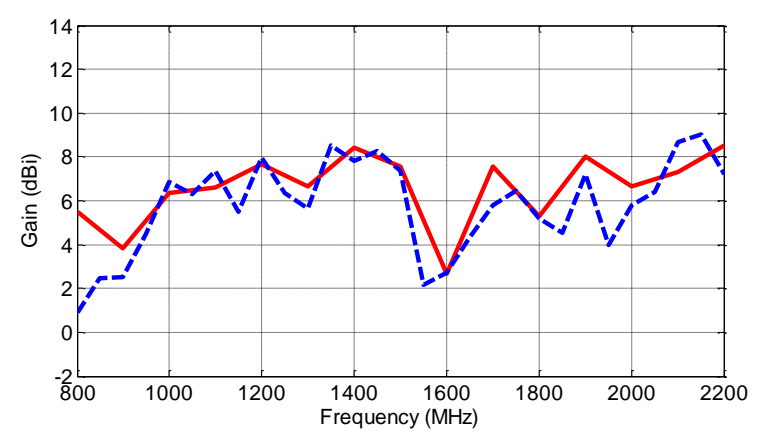

Figure 3: Total gain versus frequency. Simulation is the continuous red curve. Measurement is the dashed blue curve.

Figure 3 shows that the gain is above $0 \mathrm{~dB}$ before $800 \mathrm{MHz}$. The antenna gain value is above $6 \mathrm{~dB}$ from $1000 \mathrm{MHz}$ up to $1520 \mathrm{MHz}$. Beyond the frequency of $1600 \mathrm{MHz}$, the gain is still above $4 \mathrm{~dB}$ up to $2200 \mathrm{MHz}$, which is the upper frequency of the used $180^{\circ}$ hybrid transformer. The noticed drop of gain around $1.6 \mathrm{GHz}$ is linked to the straight connections between spiral antennas. The use of other shapes of connections (not reported here) has suppressed this gain drop.
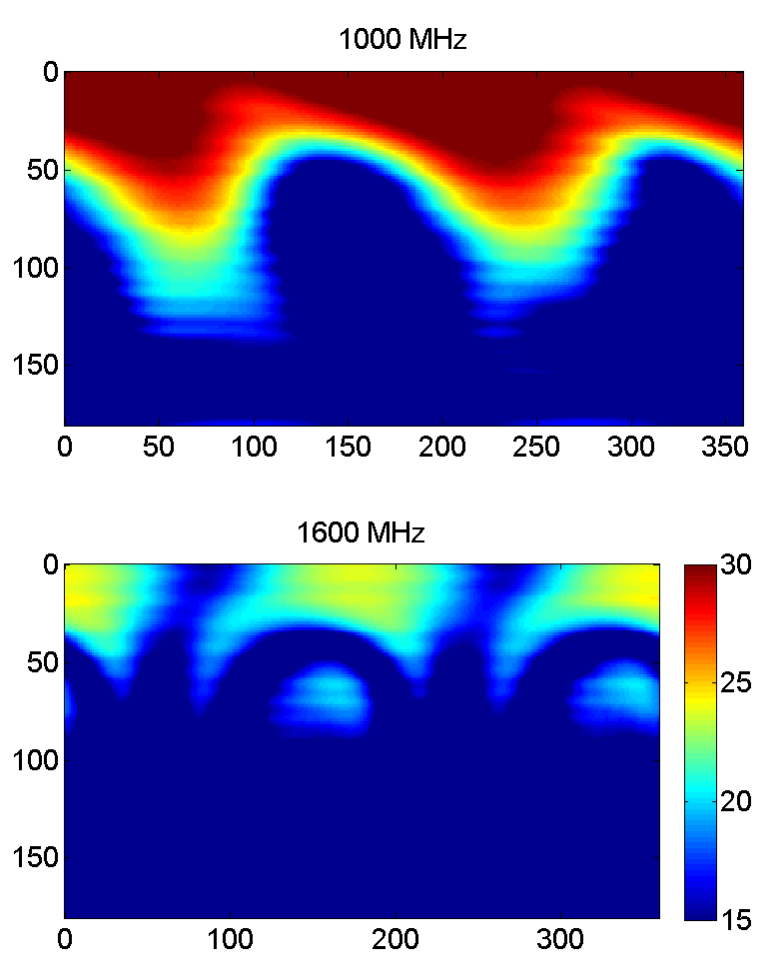

Figure 4: XpolR at two different frequencies.

Figure 4 plots the cross polarization rejection (XpolR) for two frequencies, one where the array behaves correctly (1000 $\mathrm{MHz}$ ) and the other where the gain drop is noticed (1600 $\mathrm{MHz}$ ). Data presented in Figure 4 is scaled into the 15 to 30 $\mathrm{dB}$ range as the XpolR is usually considered good above 15 $\mathrm{dB}$. Except around the frequency $1600 \mathrm{MHz}$, from $1 \mathrm{GHz}$ to $1.9 \mathrm{GHz}$, the XpolR is good for $\theta$ between $\pm 30^{\circ}$, which is a very good result. From $1 \mathrm{GHz}$ to $1.5 \mathrm{GHz}$, at broadside direction $\left(\theta=0^{\circ}\right)$, the XpolR is excellent with a wave almost perfectly circular.

\section{CONCLUSIONS}

A simple and efficient feeding of a cavity backed dual polarized array of spiral antenna has been presented. It has shown the efficiency of the feeding technique, along with the use of a simple cavity to make the radiation unidirectional. Simple straight connections were used between spirals. The next step is to build connections with improved shapes to suppress the $1.6 \mathrm{GHz}$ issue and enhance the bandwidth.

\section{REFERENCES}

[1] R. Guinvarc'h and R.L. Haupt, "Connecting spirals for wideband dual polarization phased array," Antennas and Propagation, IEEE Transactions on, vol.59, no.12, pp.4534-4541, Dec. 2011

[2] M. McFadden, W. R. Scott Jr.," Analysis of the Equiangular Spiral Antenna on a Dielectric Substrate" Antennas and Propagation, IEEE Transactions on, vol.55, no.11, pp.3163-3171, Nov. 2007 